\title{
Human nature, the environment, and behaviour: explaining the scope and geographical scale of financial decision-making
}

Gordon L Clark. Centre for Employment, Work and Finance, School of Geography and the Environment, University of Oxford, South Parks Road, Oxford OX1 3QY, UK

Contact. gordon.clark@ouce.ox.ac.uk

Abstract. This paper explores two inter-related themes. One addresses fundamental questions of human nature, arguing that conventional theories of behaviour lack a credible appreciation of the interaction between cognition and context (or what is often termed as the 'environment'). The second considers decision-making under risk and uncertainty, focusing upon customary behaviour and the significance or otherwise of conscious deliberation. My argument is intended to be both critical and constructive, exploring the claims of the emerging school of behaviouralism associated with Kahneman and Tversky now sweeping the social sciences. Most importantly, it is argued that economic geography should take more seriously the nature and scope of behaviour recognising its attributes including related social and cultural aspirations. These ideas are illustrated by a set of recent studies dealing with financial decision-making and individuals' attitudes towards risk in personal and occupational pension plans. The importance of this project lies in the urgent need to understand the diversity of behaviour of men and women in, and through, the communities in which they live without being reduced to yet another version of environmental determinism. In conclusion, implications are drawn for understanding the global financial crisis.

Keywords. Economic geography, human nature, cognition, context, finance

JEL Codes. D14, D81, G11, J12

Acknowledgements. This paper was written for the 2009 Vega Symposium honouring Allen Scott. It draws upon research with a number of my students and colleagues, especially Kendra Strauss. In this respect, I would like to thank Divyesh Hindocha for the sponsorship by Mercer Human Resource Consulting of the UK Economic and Social Research Council PhD CASE award that supported Kendra's research. As well, we have been fortunate to enlist the participation of Janelle Knox-Hayes in related research based upon data made available by Jonathan Gardner of Watson Wyatt Worldwide. The paper also bears the imprint of research sponsored by the National Association of Pension Funds on the competence and consistency of financial decision-making-Emiko Caerlewy-Smith and the late John Marshall made significant contributions to that project. I am grateful to Ashby Monk, Olga Thönissen, Kendra Strauss, and Allen Scott for comments and corrections to previous drafts. Not for the first time, I would also like to record my gratitude to Brian Berry and the late Richard Cyert for the opportunity to learn about behaviouralism at the feet of the masters. None of the above should be held responsible for any errors or omissions. 


\section{Introduction}

Economic geography is characterised by a steady flow of conceptual innovation, critical analysis, and applications to public policy and business. It spans a number of disciplines and perspectives. This does not mean that its theoretical foundations are necessarily commonly agreed. Not withstanding commitment across economics and geography to core principles of diversity, heterogeneity, and path dependence (see Clark et al. 2000 and Alesina and Glaeser 2005), there remain unresolved questions of substance such as the significance to be attributed to rationality and the legitimacy of rather different methods of analysis. For example, many geographers are uneasy about the hegemony of rationality particularly when their case studies and field research almost always raise questions about the nature of observed behaviour. But it has been difficult to build a counter-story to the rational-actor model without foundering on the rocks of environmental determinism (Strauss 2008).

Behaviouralism is often wrapped-up in dualisms such as environment and behaviour, society and space, and economy and culture. In each, there is an implied tension between structure and agency-individual behaviour is deemed dependent or contingent on fundamentals. The antimonies at work in such pairings suggest, as well, juxtaposed and competing modes of life. That they are joined together indicates a lack of confidence in the explanatory power of just one element of a pairing (such as economy compared to culture) but recognition, nonetheless, that their pairing is, in some sense, valuable. Presumably, a close reading of their interaction can provide us the means of understanding the diverse landscape of human activity. For example, "relational economic geography" seeks to combine market imperatives with the fabric of social relationships to provide a deeper understanding of geographical differentiation and path dependence (see Bathelt 2006; Bathelt and Glückler 2004).

We are not the only discipline to be preoccupied by questions of emphasis and balance, straddling the divide between formal models of market structure and performance and broader conceptions of human life. Granovetter's (1986) economic sociology is an attempt at reconciliation with applications to conventional topics like job search 
behaviour. In anthropology, culture has played a vital role in explaining differentiation between the peoples of the world being, at times, invoked as the essential building block of any society (for a critique, see Kuper 2001). Economic geography has been more circumspect than anthropology and more like economic sociology, holding to universal models of human behaviour seen through the lens of fine-grained studies about the significance of the context in which people live and work (Peck 2005). But this strategy can be accused of obfuscation (at best) or cowardice (at worst): it does not tackle the integrity of the rational-actor model that underpins most models of economic geography.

In collaboration with Strauss (2009), I sketch a means of integrating environment and behaviour without capitulating to naïve economism or grandiose gesture. Our project is informed by research on finance and pension welfare at the interface between geography and finance. This programme is concerned with financial decision-making under risk and uncertainty where respondents have social attributes and resources as well as roles and responsibilities. In part, research is based on psychological experiments and test-regimes designed to assess decision-making in theory and practice. As well, we have used econometric methods to demonstrate the significance of the socio-demographic attributes of people in risk-related decision-making. In carrying through this programme, we have been inspired by the work of Kahneman and Tversky (1979). Even so, their project has its limits-they are firmly entrenched in "cognitive individualism" rather than context and the scope of observed (social) behaviour (Wilcox 2008).

We rely upon Herbert Simon's (1956) scissors metaphor to the effect that human behaviour occurs at the intersection between cognition and the context or environment in which people live and work. ${ }^{1}$ To reap the benefits of his insights on human behaviour, we need a fully-fledged theory of cognition, a well-specified notion of context, and a theory of their interaction amendable to experimental analysis. Of course, such an integrated theory of behaviour does not exist-it is at the frontier of research in psychology and the social sciences (Henrich et al. 2005). So, this paper works from first-

\%. As such, our project seeks an expansive conception of behaviour, sensitive to diversity and affect. By contrast, neuro-economics is reductionist in intention treating economics as a natural science whose object is to develop the theory of rational choice and thereby explain behaviour (see Padoa-Schioppa 2008). 
principles: human nature and the scope of rationality. I downplay deliberation and calibrated judgement in favour of customary modes of behaviour: intuition, habit, and imitation. A way of conceptualizing the environment or context is suggested with reference to culture and society, although it is also argued that a truly geographical conception of context would be explicit about the scale of effect and affect (Thrift 2004). To illustrate, I refer to recent publications on financial decision-making drawing together the threads of our research programme on pension planning and the scale and scope of decision-making. In conclusion, lessons are drawn for understanding the geographical transformation of the sub-prime debacle into the global financial crisis.

From the outset, it should be acknowledged that this paper deals with contentious issues-rationality, behaviour, and the role of environment in shaping human life are topics that have pre-occupied anthropology and geography for many decades. The apparent generality of these issues is betrayed by profound disagreement on even the simplest issues, such as the definition of cognition, context and the environment. In the Appendix, a brief commentary on relevant definitions is provided. Notice, this paper is not intended to resolve debate once-and-for-all over their meaning or for that matter their relationships to one-another. It is no exaggeration to say that their definition is enmeshed in the much larger debate about human nature. This issue, though, has proven toxic for whole disciplines including geography. And yet, because of its claim of engagement with nature and society, it would seem incumbent upon human geography to have an explanation of behaviour that is richer than the cardboard image of rational man.

By contrast, much of decision theory is focused upon sketching a parsimonious theory of behaviour, or the standards by which to assess such a theory (Bermúdez 2009). Rarely does decision theory seek to explain the observed diversity of behaviour. Too often people are treated as one-dimensional fixed entities. If appropriate for theory-building, there are problems with such an approach not least of which is the often unquestioned assumption that people have constant utility functions-especially over time, but also over space in the sense that experience is discounted as relevant to the formation and reformation of a person's goals and objectives. 


\section{Human Nature}

We could assume that people are basically selfish, acquisitive and immoral or we could assume that people are basically sociable, cooperative and caring of others. The first "model" of human nature provides a rationale for designing institutions that protect us from one-another whereas the second "model" of human nature provides a rationale for institutions that are a framework for social action and the advancement of public welfare. Both models are universal in their scope, and are essentially normative in the attribution of motives and behaviour. ${ }^{2}$ Notice, these two models underpin competing branches of political theory and jurisprudence and the human sciences more generally (see Audi 2007). Curiously anthropology and geography are less reliant upon a single meta-theory of human nature; more often than not, we invoke "evidence" from certain times and places to select between one theory and the other.

Many in the natural sciences see human nature as the object of research rather than an $\underline{a}$ priori assumption. Without doubt, the single most important scientific model of human nature draws its inspiration from Darwin and the principles of species evolution. By this logic, whether we are selfish or altruistic, whether we are competitive or cooperative, and whether we are immoral or moral, are empirical questions set against human evolution rather than tautologies or strategic moves of argument (compare Axelrod 1986). Similarly, who we are, what we are, and what we can or can not be, are issues to be resolved by reference to our basic biological capacities, instincts, and limits: integrating our biological heritage with behaviour is one of the most important scientific projects of the $21^{\text {st }}$ century (Kahneman 2003). Nonetheless, there is disagreement about whether competition and cooperation are traits or strategies just as there is deep disagreement about the significance of human consciousness compared to other species (Hurley 2008).

\footnotetext{
2 . For example, the $17^{\text {th }}$ and $18^{\text {th }}$ century Atlantic slave trade is often invoked as evidence in favour of "model 1" whereas the sustained campaign of British religious groups to abolish the slave trade is often invoked as evidence in favour of "model 2". Recent debate about our responsibilities for others' welfare, especially in Africa and in the Middle East, work back to issues of evidence for and against competing models of human nature as well as betraying a certain moral superiority about us and them.
} 
There is, however, broad agreement about the relevance of our biological heritage for behaviour as well as for our capacity to adapt to changing circumstances. Similarly, there is broad agreement about human rationality-the logic underpinning human evolution which is presumed to be a trait rather than a strategy and is believed to be deeply embedded in our cognitive make-up rather than something that people have or don't have. It should be noted, though, cognitive scientists have sought to show that amongst human beings there is a considerable range of cognitive ability; people are not equally adept at common tasks and functions. So, for example, being numerate including being able to calculate probability is a human trait; but people are clearly not equally adept at solving such problems (Baron 2008). There is also broad agreement that differences between human beings on these types of issues are inevitable but are not attributable to social categories such as race, gender, income, or location of residence.

The biological project on human nature is a universal project and, as such, has salutary lessons for explaining endemic conflict over the status of claimed 'important' differences between people. As we share a common biological heritage, we share the same types of emotions, modes of behaviour, and predilections for competition and cooperation. To think otherwise, to imagine that 'others' are so different or unknowable, would be to conflate observed behaviour in response to certain circumstances with a claim that people from other times and places were, or are, systematically different by virtue of their human nature. If a common move of political rhetoric, orientalism is not anything more substantial than folk-stories of distant lands (Said 1978). Stating the obvious may appear trivial. But, this seems lost in contemporary debate over ethnicity, religion, and geopolitics. ${ }^{3}$

Vital for our work on finance in economic geography is the project initiated by Tversky and Kahneman (1974) on human decision-making under risk and uncertainty. Their research resonates, in the first instance, with the Carnegie-school of behaviouralism-the

\footnotetext{
3/ There are, of course, those from socio-biology that use the programme in a reductive manner such that observed differences between human beings by race, gender etc are "explained" by reference to the imperatives of environmental survival. We do not agree with this rhetorical strategy, allying our work with others such as Lewontin (1993).
} 
insights of Herbert Simon (1983) on reason and behaviour and the theory of the firm associated with Cyert and March (1978). Even so, it was ignored for many years, swamped by the momentum driving the widespread adoption of rational expectations (Lucas 1986). It slowly gained traction for a number of reasons, not least of which was the unease of leading economic theorists about the normative bases of conventional notions of rationality and the arbitrary assumptions needed to make rational expectations work in practice as desired by its advocates (Arrow 1986). Most importantly, behaviouralism was seen to be relevant to microeconomic theories of behaviour in circumstances where irreversible commitments to decision-making are subject to risk and uncertainty (Winter 1986).

All human life might be so characterised. But it is clear that Kahneman and Tversky's project was focused upon contemporary life dominated by markets and a liberal culture that favours voluntary choice and self-reliance. As such, it is easy enough to see how and why it is so important for understanding human welfare in the advanced capitalist economies of the $21^{\text {st }}$ century. ${ }^{4}$ Being able to judge the flux and flow of markets, being able to anticipate the actions of others, and being able to insure oneself against risk are crucial if individuals are to effectively plan for the future. All the evidence suggests, however, that being so able is rarer than assumed by rational choice theorists (Clark, Knox and Strauss 2009). In fact, as the global economic crisis demonstrates, relatively few people seem to be able to cope with systemic market uncertainty. These circumstances demand a level of computational and conceptual sophistication that few have at their finger-tips or even appreciate as important (Allen and Gale 2007).

Humans may be rational but are variable in their competence and consistency of decision-making. Kahneman and Tversky show that humans are risk averse to a fault, heavily discount the future, are opportunistic where a long-term perspective may be more conducive to achieving goals, and are inefficient users of information. Following in the

\footnotetext{
4. Even so, it is important to acknowledge that the contemporary significance accorded individual volition has its roots in $19^{\text {th }}$ century political philosophy associated with J. S. Mill amongst others and, indeed, UK pension policy at the end of the nineteenth century and at the start of the twentieth century; see Clark and Whiteside (2003) and Whiteside (2003) for relevant overviews of the history of UK pension policy.
} 
wake of Simon (1978), Kahneman and Tversky show that rationality is not only bounded but systematically occluded by innate cognitive biases. Recognising these traits, Gigerenzer and others (1999) suggest that humans cope by using heuristics that can compensate for these short-comings in task-specific circumstances. ${ }^{5}$ Acknowledging the existence of cognitive anomalies and biases is a way of explaining shortfalls in reasoning while providing a structured account of human behaviour in the context of risk and uncertainty. By this logic, social scientists can accept that humans are rational while appreciating the observed scope of behaviour.

\section{Taxonomy of Customary Behaviour}

In theory, at least, people make decisions in a logical manner. They begin with a set of options, assess the utility of those options against likely and desired outcomes, and choose the 'best' option assuming that they can only choose one option at any point in time (Schick 1997). The 'logic' of any action is the product of conscious deliberation. But, are people like this? Do they make decisions in this manner? These questions animate contemporary psychology and cognitive science. There is a variety of answers, most of which seem to suggest that, when people react to situations, they utilize a variety of decision-techniques most of which do not seem to require the degree of deliberation implied by rational choice theory. For example, Gigerenzer and others (1999, 13-14) reject optimization in favour of Simon's notion of satisficing and suggest that people typically use "fast and frugal heuristics" because these devices economise on time and information and can adapt to "real environments".

There are, however, significant issues to be considered, notably the mechanisms of choice amongst applicable heuristics as well as what happens when the available heuristics are not relevant. Here, there are three related problems. First, the heuristics model of decision-making may be, paradoxically, a trap. By treating heuristics as a set of decision-tools, deliberation may be reintroduced by the back-door as the means of

5 . Task-specific circumstances make serious demands on decision-making competence-well-beyond agents' general intelligence and education. This is not always appreciated in the social science literature wherein it is all about information processing rather than skill, knowledge, and substantive judgement. See Clark et al. (2006) for a specific instance and Wagner (2002) for a more general statement. 
breaking deadlocks between the available and applicable heuristics. Second, by focusing upon the instrumental nature of heuristics Gigerenzer and others seem to promise longterm decision-effectiveness: the anomalies and biases noted in everyday decision-making are presumably slowly resolved in the face of ever-finer heuristics that are applied timeand-again to perfection (Bermúdez 2009, 168). Third, for heuristics to work as expected or hoped the 'background' environment must be sufficiently stable and predictable for people to have confidence in the efficacy of inherited decision-tools. Stability is in short supply in financial markets. ${ }^{6}$ An alternative is to invoke "states-of-mind" that can do the hard work of explaining the nature and scope of behaviour without returning to heuristics or conscious deliberation.

In this regard, Hogarth (2001) suggested that intuition is an essential component in any comprehensive taxonomy of behaviour. Using synthetic examples to illustrate his argument, including one drawn from financial trading, he suggested that intuition is a form of unconscious judgement prompted by immediate circumstances and deployed without the benefit of contemplation and the steps of logic associated with the theory of rational choice. In action, the efficacy of intuition would appear to rely upon people's confidence in their ability to respond to events which in turn can be thought to rely upon the familiarity of the situation, the apparent pay-offs of one response over another, and the sense in which analogous situations were dealt with in a similar manner in the past (Kahneman and Tversky 1974). Decision-analysts believe that intuition is effective because it is immediate, it economises on the costs of conscious deliberation, and it acknowledges the lessons found in sequential action (Kahneman 2003).

Intuition is presumably subjective- - being an expression of a person's emotional state and sensibility. Consequently, intuition could be thought entirely personal, even arbitrary, when one person is compared with another and when one person's actions are tracked over time and space. Not surprisingly, there is considerable interest in 'weakness-of-

\footnotetext{
$\%$. If heuristics are expressions of past choices honed to perfection on a case-by-case basis, this is only possible if history repeats itself. The problem is that we can not be sure whether an event is a repeat of something known or the start of something new (Winter 1986). Yet, the opportunity costs of non-response can be extraordinarily high. See Clark (2008) on the scope of risk and uncertainty in financial markets.
} 
will', a notion that could be thought to represent the ennui of life (see Ainslie 2001). If important, the role of public policy is clear: those lacking confidence in their financial decision-making ought to be encouraged to develop the formal skills of decisionassessment in the hope that by trial and error they become more accustomed to making decisions against reliable benchmarks. Whether this is really possible, given that psychologists believe that confidence is innate rather than learnt, given the correlation of confidence with gender, and given the lack of reliable benchmarks is open to dispute. It does, nonetheless, underpin policies of the UK Financial Services Authority (see generally Strauss 2008).

But it would be strange to imagine that people are just spontaneous, signal-response machines unfazed by the future. In fact, a bedrock concept of behavioural and social psychology is habit. Defined by Rachlin $(2000,7)$ with reference to William James, it "functions in human life as a flywheel functions in a machine, to overcome temporary opposing forces, to keep us behaving for a time in a particular way, according to a predetermined pattern". In contradiction to the theory of choice, habit is believed to be the means by which the tyranny of choice is 'managed', replacing the exercise of deliberation time-and-again with behavioural-templates that sustain decision-making over time and space (Suppes 2003). Unlike intuition, habit can have a significant element of social regard. Habit is not only personal, it is also relational in that others may rely upon the habits of people they know so as to anticipate their actions. Equally, habit may claim a certain cultural affectation that makes it a shared set of behavioural norms and customs. $^{7}$

Habits are like heuristics in that they provide recipes for action. But the contrast drawn here is between habits as practice and heuristics as decision-tools wherein the former is representative of patterns of unconscious behaviour in certain environments whereas the latter is representative of a method of deciding what action to take given the known

\footnotetext{
7 . There are many ways of illustrating these two points. Consider, for example, the back-page of the "How to spend it" section of the Weekend Edition of the Financial Times. There guests recount their habits of weekend relaxation often invoking their preferred retreats, what they eat and where they eat, and how much they value (as their families value) the re-assuring nature of affective pleasures in well-defined environments. See, "Perfect Weekend: Camille Goutal" Financial Times, May $2^{\text {nd }} 2009$, p.62.
} 
options. Because habits are formed in relation to the expectations of others that rely upon their performance, our reference point here is also Harré's (1993) notion of "social action as problem solving". As such, it is an expansive notion of behaviour that is related, in part, to seeking others' approval and appreciation. By this logic, habit is derivative; being part of a larger set of actions and affectations when taken as a whole are the life of human beings. If this sounds vague and somewhat normative (how people properly live), evidence for it can be found in our research on pension planning where there appears to be a premium on intimate relationships with others (Clark, Knox and Strauss 2009).

Habit provides a template for behaviour over time and space. Going further, analysts believe that imitation is the means by which behaviour is anchored in society and culture. Imitation is, simultaneously, innate and socially conceived. It is one of the basic mechanisms by which people (and animals) learn from others. As such, it underpins human development. If believed simple-minded, Hurley (2008) suggested that it is actually a sophisticated and difficult to realise ambition given the costs of adapting behaviour to that which is held to be desirable and given the costs of sorting through the interaction between the environment and behaviour to identify that which can be copied. We also imitate those who we respect and admire. We do so even though they may live in a world quite different from us. In this sense, imitation need not be particularly effective or efficient-it commonly represents deeply held aspirations which are often valued in their own right (beyond the expected consequences of imitation).

We could argue that the locus of intuition, habit, and imitation is necessarily 'local' if what we do in reaction to events and circumstances is informed by who we are in relation to where we live and work (Camerer 2008, 371). Recent empirical research that has shown the relevance of this scale of life for framing decision-making resonates with many human geographers (see Schwanen and Ettema 2009). The idea that behaviour is ipso facto 'local' is also consistent with our disciplinary expectations and commitments (Smith and Easterlow 2005). We would suggest, though, that if intuition and habit are inherently 'local', the spatial coordinates of imitation may be more difficult to allocate to just one spatial scale. Imitation is relational albeit relational at a variety of embodied and 
dis-embodied scales. We are, in any event, sceptical of the premium attached to the 'local' believing that there is a strong normative claim often embedded therein which supposes that the 'local' is the 'proper' scale of life against the scaling-up effects of globalization and information technologies (Couclelis 2009). The geographical scale of intuition, habit and imitation should be subject to the same empirical scrutiny as risk aversion etc.

\section{Practice of Decision-making}

Kahneman and Tversky's project is especially relevant to the contemporary world dominated, as it is, by market imperatives. In this respect, the context of their project, and other related projects on human reasoning such as Herbert Simon's, sets the parameters for the possible scope of individual decision-making even if context is not determinant of behaviour. As such, behaviour is embedded in the ensemble of market institutions that are, more or less, representative of the effective structure and organisation of capitalist society. Here, there are obvious connections to be made with the relevant social science literature including Polanyi (1944) and Miller (2002) who believe that context matters a great deal. Similarly, Scott's (2008) work on the economic and social foundations of modern capitalism provides useful clues as to the origins of observed differences of behaviour between different types of people (by their employment and income).

Market economies are characterised by constant change, whether by growth or creative destruction. By this logic, life is calibrated against the temporal rhythms of the economy, and is reflected in social relationships and customary practice (Thrift and Glennie 2005). Market economies also have deeply engrained and distinctive spatial configurations. From a political economy perspective, economies make places what they are including their social relationships and institutions-just as importantly, places make capitalist economies distinctive as explained by political scientists and sociologists through the logic of "varieties of capitalism", and by economic geographers committed to the logic of path dependence and clusters of innovation (Peck and Theodore 2007). Inevitably, individual decision-making under risk and uncertainty is entwined with the temporal and 
spatial configuration of modern economies. ${ }^{8}$ Time and space are both constitutive and derivative of the nexus between environment and behaviour.

Context stands for the macro or structural logic of decision-making setting the parameters for behaviour. If an exercise in categorical distinction, this way of expressing the issue provides a roadmap for empirical analysis. Nonetheless, it is unsatisfactory for a number of reasons. First and foremost, it privileges the economic over other social and political systems-social and political life appears derivative of the economic sphere. This is not intended. Rather, it is the inevitable result of a certain emphasis on those contemporary environmental forces that structure decision-making under risk and uncertainty. As such, it is an analytical strategy rather than a historical approach to the evolution of economic, social and political institutions that might provide for different conceptions of the proper significance of one sphere of life over others (Engelen 2003). If it is silent about culture, there are obvious links to be made to the cultural turn in economic geography (see Scott 2006; Scott and Power 2004).

Consider the significance of two types of widely-recognised behavioural traits. The accumulated research suggests that people have high discount rates (to the extent they have coherent discount functions), are slow to respond to changing circumstances, and generally value the near-future over long-term plans even if this behaviour is known to be to their detriment (Ainslie 2001). Similarly, research suggests that people are poor at searching for relevant information, tend to act on the basis of immediate experience, and find probabilistic reasoning problematic. In sum, they are myopic: they rely upon what they know even if that is specific to certain times and places (see Kahneman et al. 1997 and Sedlemeir and Gigerenzer 2001). ${ }^{9}$ These traits suggest that, in the absence of cues to

\footnotetext{
8\% As suggested by Langley (2008), the hegemony of finance is a distinguishing feature of $21^{\text {st }}$ century capitalism where the temporal contingency of individual wellbeing has permeated the fabric of everyday life in western societies. The global financial crisis has served to make this transparent, and to appreciate the scope of financialization in western economies.

$\%$ It should be recognised that these traits are just two sets of a growing list of so-called biases and anomalies. Krueger and Funder (2004) identified about 40 such biases and Baron (2008), in the latest edition of his book, listed about 60 such biases. Notice that the implied order of these two sets of biases may not be stable in the sense that the evidence suggests people are susceptible to over- and under-reaction
} 
the contrary, people tend to act local: the significance of an event or opportunity is perceived through the lens of what they know and they are hostage to events that happen elsewhere and feed-back over time into their immediate 'environments'. ${ }^{10}$ Contrary to models of recursive learning in the formation of market prices (Vives 2008), most people are not Bayesian analysts (as in the agenda sketched by Oakford and Chater 2007).

That people respond to events through intuition, habit, or imitation and that the temporal and spatial scope of response is customarily local rather than global provides a datum against which to analyze behaviour (as suggested by Hägerstrand's 1970 'time geography'). But, we must take care not to exaggerate the significance of these findings suggesting directly or by implication that customary behaviour exhausts the repertoire of possible behaviour. Here, though, expectations break two ways. There are those, like Kahneman (2003), who believe that most people, most of the time, behave within the parameters set by cognition and context trading on the cues available from each blade of the scissors to arrive at satisfactory outcomes. In this respect, and in contrast to those who hold fast to the theory of subjective expected utility maximisation, satisficing is not only the 'normal' response to events, it is socially acceptable in the sense that others similarly inclined set the norms of expected behaviour (an explanation of herding behaviour in financial markets that has a strong cultural overlay; see Shiller 2002).

This is an invitation to take steps to at least dampen or manage the effects of myopia if not expunge it from human reasoning (Doherty 2003). But it takes conscious deliberation and conceptual understanding to break with that which comes naturally and thereby transcend the local in favour of the global. ${ }^{11}$ A number of arguments or propositions can

to the environment and that governing these types of reactions may take more conscious deliberation than many people seem willing to commit.

${ }^{10}$. This is expressed in many different ways relevant to economic geography and financial theory. See, for example, Huberman (2000) and Wójcik (2009) on 'home-bias' (the observation that portfolio managers tend to over-load on local securities) and Huberman (2001) on the apparent value attributed by investors to 'familiarity' (the observation that individuals tend to invest in local companies, even over-loading on the stock of the companies that employ them). See also Clark and Wójcik (2007).

${ }^{11}$. Recent research on the management of labour markets from the local to the global reminds us that public and private institutions can play important roles in transcending the local in favour of the global 
be made to the same effect: people can be taught to reflect on their plans prior to taking action and the possible pay-offs to deliberation based upon non-experiential information sources from distant sites of activity may encourage reflection prior to action (Couclelis 2009). Embedded in this multi-factor argument are a supposition and an empirical project - the supposition is that reflection is as much about information acquisition as it is about deliberation. The empirical project is to show how the available resources including information (or lack thereof) contribute to the exercise and quality of conscious deliberation and the sense in which making a break with customary practice has shortterm and long-term value for those concerned.

This implies the existence of a range of responses to a common environment partly driven by the scope of reflection as well as the spatial distribution of information resources that, in some way or another, encourage more or less informed reflection. We could also invoke Hogarth's (2001) suggestion that some environments are more or less conducive to human reasoning and that a predilection in favour of reflection is mediated through the social resources needed to effectively evaluate the options for action. As well, Scott's (2008) thesis that modern capitalist societies rely upon cognition and culture for the production of value may be especially significant, providing a rationale for the internal stratification of societies wherein people occupy certain roles and responsibilities that require (or do not require) the deliberate exercise of judgement. By this logic, the scope of observed behaviour-beyond intuition, habit, and imitation-is 'produced' by society (the environment) and is 'regulated' by the performative requirements (context) that attend certain social roles and responsibilities. ${ }^{12}$

To illustrate, consider the implications of two recent papers by McDowell (2008) and McDowell et al. (2009) on the stratification of the UK labour market and the demand for certain types of job-specific 'skills'. In her work, like Scott (2007), the labour market is

thereby discounting the cognitive skills needed by individuals to make the leap beyond everyday life (see, generally, McDowell et al. 2008).

${ }^{12}$. We show in Clark et al. (2007) that people with task-specific expertise and domain-specific knowledge tend to be better than neophytes at solving investment-related problems. That is, the domain in which they live and work is an essential ingredient in how they respond to risk and uncertainty. 
usefully divided into two: at one level, there are relatively high-paid and secure jobs that require education and formal training and skills. At the other level, jobs are insecure, poorly paid, and require little in the way of formal education. These jobs require "deference and courtesy" rather than calibrated judgement and fine-tuned response to changing circumstances. In other words, the nature of work can provide "kind" environments (at the first level) that reward the exercise of judgement and deliberation in ways that reinforce the value of these skills, and "wicked" environments (at the other level) that deliberately discount the value of such skills in favour of 'performance' regulated by discipline and conformity. We know little about the cross-over effects of social roles and responsibilities in specific settings for the nature and scope of 'private' behaviour. But, the implications are plain.

For some analysts, the high level of cognitive skills needed to perform some types of work in modern economies represents a possible pathway back to reason and rationality albeit highly stratified and segmented. So, for example, governments around the world have promoted informed decision-making amongst those people who have the cognitive capacity and material interest in so acting hopefully triggering individual tendencies of self-reflection and responsibility (in the face of the looming social costs of ageing and welfare). By contrast, Thaler and Sunstein (2008) have argued that it is better to work with customary behaviour rather than against innate traits to foster desirable individual and social outcomes. By this logic, institutions are best advised to design 'channels' or 'streams' of action-in-response to the environment such that these devices prompt behaviour that 'automatically' transcends the myopia of cognition and context. Implicitly, perhaps, Thaler and Sunstein suggest that the discounting of cognition in many segments of the modern economy means that there is a real need for institutions that can compensate for the lack of calibrated judgement in everyday life.

\section{Behavioural Economic Geography}

The behavioural revolution has most to say about our cognitive heritage, less to say about the role of the environment in affecting behaviour, and has even less to say about how Simon's scissors function (that is, the neurological interaction between cognition and 
context). Further more, the vast majority of published studies of cognitive function and performance rely upon the responses of university students (undergraduates and postgraduates) to accepted problems and puzzles (Baron 2008). That these puzzles are replicable, have established protocols for implementation, and carry with them recognised patterns of likely outcomes provides those working in the field a tool-bag of controls and methods. Without these protocols it is doubtful that the behavioural revolution would have been anything more than a critique of the assumptions and methods of economics (as much of economic geography seems to be).

However, the respondents of most studies are naïve and inexperienced. They have little or nothing at stake in their responses. This is deemed, by many, to be an advantage in that age and experience may prompt second-order disputes over the design of puzzles that are confounded by everyday life. Still, the institutional context of these experimental regimes is unsettling. At best, these respondents provide us a base-line for testing variations in cognitive function and performance (Clark et al. 2006). At worse, utilizing these respondents in plain-vanilla settings implies a set of troubling assumptions. First, that these respondents are representative of society; second, that social identity, roles, and responsibilities are irrelevant in assessing cognitive function and performance and; third, that education, experience, and task-specific decision-routines only mediate cognitive traits. Not withstanding the fact that experimental protocols are set so as to be relevant to risk and uncertainty, there is also little appreciation of culture-specific definitions of risk (Douglas and Wildavsky 1983).

By raising these concerns, I do not mean to overturn what has been achieved-cognitive traits do not evaporate once we take into account culture or society. Rather, there remain crucial empirical issues to be resolved. For example, can age, experience, and taskspecific education and training make up for apparent short-falls in cognitive function and performance amongst naïve respondents? We think so, as do others especially those convinced of the significance of learning (individual and social) (Doherty 2003). If, as we believe, there is a natural bias in favour of that which people directly know and experience, is behaviour always 'local'? Are there 'tricks' that can enable people to 
work-up the geographical scale of perception and behaviour? Answers to these questions have enormous implications for human development (cognitive and social), just as they have enormous implications for understanding the map of economic development and human welfare (within and between countries).

We are convinced that social roles and relationships make a difference to the consistency of decision-making under risk and uncertainty (Clark et al. 2007). This can be an argument about measured cognitive function and performance; it could also be a theoretical argument about human nature, referencing the innate sociability of human beings. One of the short-comings of Kahneman and Tversky's research programme is its exclusive focus on individual behaviour (Kreuger and Funder 2004). On this point, Baumeister $(2004,15)$ stated that "the need to belong is a central feature of human motivation" and that emotional attachment can sustain decision-making even when the scope of risk and uncertainty is such that individuals are paralysed by inaction. Equally, social rejection can prompt a level of emotional distress that scuttles even the simplest of decision-rules. Missing from many accounts of decision-making are the social commitments and relationships that are expressed through intuition, habit and imitation and mediate cognitive biases.

To illustrate, in Clark and Strauss (2008) we test whether it matters if people are young or old, male or female, and with a spouse or not for individual risk assessment. Using a set of questions designed to elicit respondents' decision-making with regard to risk and uncertainty it was found that risk behaviour and predisposition were correlated with socio-demographic status and income, and that having a partner with a pension entitlement makes a difference to risk propensity all things being equal. It was also found that poor, single women are highly risk averse and appear to heavily discount the future. In effect, social identity and relationships are correlated with individual risk-management strategies-some people make plans for the future based upon their intimate relationships with others (see also Freidberg and Webb 2006). Respondents' savings behaviour is shaped by their immediate relationships with others, and is therefore 'local' albeit with two possible effects, positive and negative. 
In Clark, Knox and Strauss (2009), we begin with research about the scope of conscious deliberation. We rehearse the argument (above) about the limits of deliberation, thereby providing a taxonomy of planning-from the reactive, the responsive, to the deliberately forward-thinking. Here, we were interested in who is a planner and who is not. As in the previous paper, we were able to show that social identity, age and income along with intimate relationships with others makes a significant difference to the nature and scope of deliberation. ${ }^{13}$ We also sought to determine whether people scale-up their search for advice and information in making planning decisions: that is, whether people are always 'local' or use geographically remote, dis-embodied sources of information such as the internet in calibrating their plans. We found that local relationships dominate disembodied and institutional sources of advice and information. Our respondents rely upon those they know whether by trust or by contract (contra Couclelis 2009).

Notice, though, the interpretation of these results is open to two possible arguments. On one side of the equation, planning may reinforce social advantage and the value of existing beneficial relationships (wherein planning is an instrumental strategy). On the other side, planning may be derivative of social status in that it refers to shared aspirations for the future reinforced by their relationships with others rather than the tactical advantages of social status (an argument about culture and context). Unresolved is whether people plan for the future because they can, because their peers do so, or because the available resources including advice match their expectations of the necessary 'localness' of salience and significance.

Clark and Knox (2007) combine a commitment to understanding the nature and scope of decision-making with the realisation that changing economic circumstances, filtered through region of residence, can make a difference to decision-making. Through an analysis of the intended take-up (or not) of annuities at different ages post-retirement, it is

\footnotetext{
13\%. Our findings for the UK match those of Lusardi and Mitchell (2007) for the US wherein they show that many people do not "plan" for retirement, and that those that do plan are amongst the better educated and well-off of society. Those that do not plan are poor, the least educated, and are from minority households.
} 
shown that social status and identity interact with geographical location to produce highly differentiated maps of personal initiative. This study was cast in the aftermath of the 1990s stock market bubble (post-9/11) and sought to test observed responses against continuing debate over the value of annuities by social status and location of residence. It was found that the UK map of private pension benefits is significantly related to social status and that the intended take-up of an annuity is significantly related to the region of residence of respondents - there is, in effect, a UK map of risk (and non-risk) cultures such that reliance upon financial markets systematically varies by region. ${ }^{14}$

Going further, in Clark and Knox (2009) we ask who would exercise control over the management of their pension plans. This is an important issue. The Chicago-school of libertarian paternalism exemplified by Thaler and Sunstein (2003) believe that pension providers ought to take advantage of the lack of interest of people in pension planning. They would deliberately frame the options available for participants so as to dampen the effects of cognitive biases on participants' management and control of their pension savings. We find that those plan participants who would claim control over crucial decisions taken with respect to their pension welfare have many of the same characteristics as pension savers noted above, including their reliance on partners for planning effectiveness. Libertarian paternalism comes close to coercion when the design of decision-making options so channels participants' behaviour as to deny their initiative. This may be justified by reference to those willing to accede to the power of the benevolent 'planner'. But the point here is that paternalism can coerce even if coercion is deemed in the best interests of most people.

We are aware that these studies simply set an agenda for further research. Moreover, our analytical strategy assumes that context (market risk and uncertainty) and the myopia of respondents frame the decisions taken about pension and retirement planning. This is a fairly conventional view of the relationship between market ("top") and behaviour ("bottom"). Missing is a story about how risk cultures affect the perception of risk and

\footnotetext{
14 . These findings resonate with recent research by Leyshon et al. $(2004,2005)$ and others on the "financial ecology" or landscape of UK cities and regions as regards the production and consumption of certain types of financial products.
} 
uncertainty such that intuition, habit and imitation are the mechanisms through which those perceptions translate into distinctive space-time patterns of pension planning. If this can be shown to be systematic, we will also need a story about the production and reproduction of risk cultures that goes beyond commonplace assumptions that risk cultures are myopic. In effect, we need to make good on increasing evidence that financial products and market performance are the result of context and behaviour (Hong et al. 2004, 2005). By this logic, there may be no "top" and no "bottom" so much as the simultaneous formation of market and behaviour (Abolafia 1996).

\section{Implications and Conclusions}

For at least a couple of generations, the rational agent model dominated disciplines such as economics, skewed innovation in disciplines such as political science, and discounted the insights of disciplines such as anthropology and geography. We became very cautious of being 'tagged' as environmental determinists, recognising the costs of being tarred with any brush that in some way denied the principle claim of the rational actor model: humans are, by definition, rational (in a strong sense). Curiously, this claim was advanced not through rigorous empirical evidence but by an unjustified rhetorical move: a presumption in favour of rationality enforced by the mandarins controlling the major journals of academic disciplines. If there was any doubt, it was expunged by exhortations to 'model' behaviour as if it was rational. It was a short step to the design of public policy and regulation along these lines.

The costs of this rhetorical strategy for the social sciences have been significant. Empirical traditions were subsumed under the weight of a priori assumptions where stylised facts occupied the space left vacant by the lack of research. So, for example, the assumption (believed owed to Paul Samuelson) that people have well-defined discount functions was not challenged until Kahneman and Tversky began to test for timepreference and value. It is remarkable, in fact, that social scientists should have assumed that people have coherent time-preferences given the everyday evidence close at hand. It took Ainslie's (2001) path-breaking research to raise doubts about this assumption. The assumption that people are super-rational ignored the very stuff of life including human 
emotions, values, and social relationships. To the extent these issues were raised within the rational actor paradigm they were assigned a supporting role, at best, in the search for 'explanation'.

The costs of this strategy for society have been nothing less than catastrophic. Consider recent history. If people are rational qua rational, there is no such thing as an asset bubble in financial markets. If they are rational, they are not self-defeating. If they are rational, they search for value and price accordingly. If they are rational, expectations converge on some measure of 'reality' (Huberman 2003). In other words, if market agents were as rational as the rational actor model would have it then local bubbles would not, and could not, morph into global depressions. Until recently, few academics were willing to dispute the rational actor model. Those that did, like Shiller (2000), did so observing the psychology of market pricing and the ways in which people herd together in market-chasing episodes of boom and bust. It is surely no accident that his insights about these issues were formed through detailed knowledge of the performance of US regional housing markets.

If the presumption of rationality is the Achilles heel of financial regulation, how can we explain the systemic nature of the global financial crisis? There are, no doubt, many viable explanations. An academic industry is being formed around the topic which will last at least a generation, animated, in part, by the significance of derivatives and collateralised debt obligations (CDOs), the parcelling and distribution of risk, and the role of institutions such as AIG Financial Products Corp. in spreading risk around the world. It is important to 'explain' the behaviour that brought markets to collapse (Akerlof and Shiller 2009). Here, intuition, habit and imitation can each play a role in the story. Whereas CDOs and the like were opaque, intuition became the dominant 'method' of evaluation. Whereas the pricing of risk was done in a rather benign environment, habits of pricing and risk assessment proved to be self-defeating as the market itself turned against those habits (and the underlying methods of assessment). Whereas CDOs were first taken up by US institutions, investors around the world imitated the actions of those that claimed a risk-and-return premium on such investment. 
Was it this simple? Probably not. ${ }^{15}$ To understand how and why imitation spread CDOs around the world also requires an appreciation of the changing global financial environment in the aftermath of the TMT bubble. The surging volume of savings in global markets combined with declining equity premiums in developed economies' securities markets meant that institutional investors were forced into less transparent products and markets promising higher risk-adjusted rates of return. The apparent risks associated with the lack of experience of many institutions in these segments were glossed-over by virtue of the integrity attributed to US ratings agencies and the fact that many reputable US financial institutions like AIG Financial Products Corp. claimed to stand behind the offered products - it seems that the further an institutional investor was away from the US, the greater was the reliance of that investor on the presumed integrity of risk-ratings and the institutions offering products. In these ways, the changing global financial environment played an important role in driving otherwise savvy investors to the margins of markets they were neither knowledgeable of nor able to assess with skill.

Also important was the fact that those touting CDOs and those seeking to purchase these types of products were willing to assume a level of risk on behalf of their institutions that they would probably not have assumed for themselves. The fact that many advisors and institutional decision-makers did not understand the assumed risk was glossed over with expressed 'confidence' and 'trust' in originators. The institutional context of (limited) risk assessment and the short-term rewards that flowed to those located either side of these transactions conspired to turn initial market scepticism into a stampede for access to these investments before the market 'closed'. Regulators were caught-up in a culture of shared assumptions and expectations as regards the efficiency of market pricing even though the available rewards favoured the flow of transactions and discounted the probability of a systemic crisis. Given the nature of financial markets, this culture of shared expectations was amplified by imitation and the suspension of belief; such cultures are the enemy of human welfare.

\footnotetext{
$15 \%$ Even so, see Tett $(2009,77-82)$ on the competitive pressures on banks for produce 'exotic' products for institutional consumers around the world that seemed rather ignorant of the underlying properties of desired derivative products.
} 


\section{Appendix. Nomenclature}

Cognition is "the act of thinking" (Hogarth 2001, 15-16). This statement is intended to be descriptive rather than prescriptive. Hogarth suggests that most thinking is neither conscious nor deliberate. If we assume, for the moment, that thinking is analogous to information processing, cognitive scientists believe that processing is typically automatic and reliant upon mechanisms that "are hardwired in the sense that they are part of our genetic inheritance". Because information-processing routines are assumed second nature, it is contended by experimental scientists that these routines are based upon "experiential learning and, as such, (are) specific to particular domains" or environments (p. 23). Therefore, learning need not be effective or even possible (see Gertler 2001 on the limits of learning between jurisdictions).

The environment is normally described in physicalist terms: that is, the environment is the world around us, where we act, what we are affected by and, in turn, that which is affected by our actions. More often treated as a concept than a 'real' place, in psychology it is assumed to have the resources needed for humans to survive, if not always prosper (see Gigerenzer and Todd 1999, 13). Hogarth (2001, Ch. 3) suggested a taxonomy of environments referring to "kind" and "wicked" environments wherein the former are favourable to learning while the latter are not. See also Smith and Easterlow (2005) on "(Risky) Spaces" and "(Healthy) Spaces" and the limits of environmentcentred explanations of human morphologies. For all the significance attributed to the environment in human behaviour, it is often treated as a passive element in human life. As an exception, see Atusti and Harris (2008) for an imaginative analysis of the interaction between cognition and the environment showing that children's conceptual development is dependent, in part, on their tactile engagement with the environment.

Context is typically used in two related ways. In many respects, it is simply short-hand for the environment (as implied by Smith and Eaterlow 2005). In some cases, though, context has a narrower meaning referring to the specific domain in which behaviour takes place including agents' roles and responsibilities as well as the social commitments 
related to that domain (Hogarth 2001, 230-31). By this interpretation, context is shorthand for the frame or parameters that set the probable social and geographical scope of behaviour. ${ }^{16}$ See the volume edited by Pettit and McDowell (1986) on the philosophical status of context in relation to behaviour. Glennie and Thrift $(2009,395-397)$ use the concept to explain what prompts innovation, arguing that analysts who emphasize the initiative of lone inventors miss the crucial significance of "regional and local networks and temporalities" and, in particular, "communities of practice".

\section{References}

ABOLAFIA, M. (1996): Making Markets: Opportunism and Restraint on Wall Street. Harvard University Press, Cambridge, MA.

AKERLOF, G. A. and SHILLER, R. J. (2009): Animal Spirits: How Psychology Drives the Economy, and Why it Matters for Global Capitalism. Princeton University Press, Princeton.

AINSLIE, G. (2001): Breakdown of Will. Cambridge University Press, Cambridge.

ALESINA, A. and GLAESER, E. L. (2004): Fighting Poverty in the US and Europe: A World of Difference. Oxford University Press, Oxford.

ALLEN, F. and GALE, D. (2007): Understanding Financial Crises. Oxford University Press, Oxford

ARROW, K. J. (1986): 'Rationality of self and others in an economic system', Journal of Business 59: S385-99.

ASTUTI, R. and HARRIS, P. L. (2008): 'Understanding mortality and the life of the ancestors in rural Madagascar', Cognitive Science 32: 713-740.

AUDI, R. (2007): Moral Value and Human Diversity. Oxford University Press, Oxford.

AXELROD, R. (1984): The Evolution of Cooperation. Basic Books, New York.

BARON, J. (2008): Thinking and Deciding. $4^{\text {th }}$ edn. Cambridge University Press, Cambridge.

\footnotetext{
$16 \%$ The notion of framing is also utilised, with variations, in social theory as in anthropology (for example, Goffman 1974), the study of social control (Foucault 1977, 1979), and market systems (Callon 1998). This connection is explored in Strauss (2008, 2009).
} 
BATHELT, H. (2006): 'Geographies of production: growth regimes in spatial perspective 3 - toward a relational view of economic action and policy', Progress in Human Geography 30: 223-36.

BATHELT, H. and GLÜCKLER, J. (2005): 'Resources in economic geography: from substantive concepts towards a relational perspective', Environment and Planning A 37: 1545-63.

BAUMEISTER, R. F. (2004): 'The psychology of irrationality: why people make foolish, self-defeating choices', in BROCAS, I. and CARTILLO, J.D. (eds): The Psychology of Economic Decisions. Volume 1: Rationality and Well-Being. Cambridge University Press, Cambridge, pp. 3-16.

BERMÚNDEZ, J. L. (2009): Decision Theory and Rationality. Oxford University Press, Oxford.

CALLON, M. (1998): The Laws of the Markets. Blackwell Publishers, Oxford.

CAMERER, C. (2008): 'The potential of neuroeconomics', Economics and Philosophy 24: 369-79.

CLARK, G. L. (2008): 'Governing finance: global imperatives and the challenge of reconciling community representation with expertise', Economic Geography 84: 281302.

CLARK, G. L., CAERLEWY-SMITH, E. and MARSHALL, J. C. (2006): 'Pension fund trustee competence: decision making in problems relevant to investment', Journal of Pension Economics and Finance 5: 91-110.

CLARK, G. L., CAERLEWY-SMITH, E. and MARSHALL, J. C. (2007): 'The consistency of UK pension fund trustees' decision-making', Journal of Pension Economics and Finance 6: 67-86.

CLARK, G. L., FELDMAN, M. and GERTLER, M. S. (eds) (2000): The Oxford Handbook of Economic Geography. Oxford University Press, Oxford.

CLARK, G. L. and KNOX-HAYES, J. (2007): 'Mapping UK pension benefits and the intended purchase of annuities in the aftermath of the 1990s stock market bubble', Transactions, Institute of British Geographers 32: 539-55.

CLARK, G. L. and KNOX-HAYES, J. (2009): 'The 'new' paternalism, consultation and consent: expectations of UK participants in defined contribution and self-directed retirement savings schemes', Pensions: An International Journal 14(1):58-74.

CLARK, G. L., KNOX-HAYES, J. and STRAUSS, K. (2009): 'Financial sophistication, salience, and the scale of pension planning', Environment and Planning A (forthcoming). 
CLARK, G. L. and STRAUSS, K. (2008): 'Individual pension-related risk propensities: the effects of socio-demographic characteristics and a spousal pension entitlement on risk attitudes', Ageing and Society 28: 847-74.

CLARK, G. L. and WHITESIDE, N. (2003): 'Introduction', in CLARK, G. L. and WHITESIDE, N. (eds): Pension Security in the $21^{\text {st }}$ Century: Redrawing the PublicPrivate Divide. Oxford University Press, Oxford, pp. 1-20.

CLARK, G. L. and WÓJCIK, D. (2007): The Geography of Finance. Oxford University Press, Oxford.

COUCLELIS, H. (2009): 'Rethinking time geography in the information age', Environment and Planning A doi:10.1068/a4151

CYERT, R. AND MARCH, J. (1963): A Behavioral Theory of the Firm. Blackwell, Oxford

DOHERTY, M. E. (2003): 'Optimists, pessimists, and realists', in SCHEIDER, S.L. and SHANTEAU, J. (eds): Emerging Perspectives on Judgement and Decision Research. Cambridge University Press, Cambridge, pp. 643-79.

DOUGLAS, M. and WILDAVSKY, A. (1983): Risk and Culture. University of California Press, Berkeley.

ENGELEN, E. (2003): 'The logic of funding European pension restructuring and the dangers of financialization,' Environment and Planning A 35: 1357-72

FOUCAULT, M. (1977): Discipline and Punish: The Birth of the Prison. SHERIDAN, A. (trans). Allen Lane, London.

FOUCAULT, M. (1979): The History of Sexuality. HURLEY, R. (trans). Allen Lane, London.

FRIEDBERG, L. and WEBB, A. (2006): Determinants and consequences of bargaining power in households. Working Paper 12367, National Bureau of Economic Research, Cambridge, MA.

GERTLER, M. S. (2001): 'Best practice? Geography, learning and the institutional limits to strong convergence', Journal of Economic Geography 1: 5-26

GIGERENZER, G. and others. (1999): Simple Heuristics That Make Us Smart. Oxford University Press, New York. 
GLENNIE, P. and THRIFT, N. (2005): 'Revolutions in the times. Clocks and the temporal structures of everyday life', in LIVINGSTONE, D. and WITHERS, C. (eds): Geography and Revolutions. University of Chicago Press, Chicago, pp. 160-98.

GLENNIE, P. and THRIFT, N. J. (2009): Shaping the Day: A History of Timekeeping in England and Wales 1300-1800. Oxford University Press, Oxford

GOFFMAN, E. (1974): Stigma: Notes on the Management of Spoiled Identity. New York, Aronson.

GRANOVETTER, M. (1985): 'Economic action and social structure: the problem of embeddedness', American Journal of Sociology 91: 481-510.

HÄGERSTRAND, T. (1970): 'What about people in human geography?' Papers, Regional Science Association 24: 7-21

HARRÉ, R. (1993): Social Being. Blackwell, Oxford.

HENRICH, J. and others. (2005): "Economic man" in a cross-cultural perspective: behavioural experiments in 15 small-scale societies', Behavioural and Brain Sciences 28: 795-815.

HOGARTH, R. M. (2001): Educating Intuition. University of Chicago Press, Chicago.

HONG, H., KUBIK, J. and STEIN, J. (2004): 'Social interaction and stock-market participation', Journal of Finance 59:137-63.

HONG, H., KUBIK, J. and STEIN, J. (2005): 'Thy neighbour's portfolio: word-of-mouth effects in the holdings and trades of money managers', Journal of Finance 60:2801-824.

HUBERMAN, G. (2000): 'Home bias in equity markets: international and intranational evidence', in HESS, G. D. and van WINCOOP, E. (eds): Intranational Macroeconomics. Cambridge University Press, Cambridge, pp. 76-91.

HUBERMAN, G. (2001): 'Familiarity breeds investment', Review of Financial Studies 14: 659-680.

HUBERMAN, G. (2003): 'Behavioural finance and markets', in DIMITRI, N., BASILI, M. and GILBOA, I. (eds): Cognitive Processes and Economic Behaviour. Routledge, London, pp. 1-14.

HURLEY, S. (2008): 'The shared circuits model: how control, mirroring, and simulation can enable imitation, deliberation and mindreading', Behavioural and Brain Sciences 31: $1-22$. 
KAHNEMAN, D. (2003): 'Maps of rationality: psychology for behavioural economics', American Economic Review 93: 1449-75.

KAHNEMAN, D., SCHWARTZ, A., THALER, R. and TVERSKY, A. (1997): 'The effect of myopia and loss aversion on risk taking: an experimental test', Quarterly Journal of Economics 112: 647-61.

KAHNEMAN, D. and TVERSKY, A. (1979): 'Prospect theory: an analysis of decisions under risk', Econometrica 47: 263-91.

KRUEGER, J. I. and FUNDER, D. C. (2004): 'Towards a balanced social psychology: causes, consequences, and cures for the problem-seeking approach to social behaviour and cognition', Behavioural and Brain Sciences 27: 313-28.

KUPER, A. (2000): Culture. Harvard University Press, Cambridge, MA.

LANGLEY, P. (2008): The Everyday Life of Global Finance. Oxford University Press, Oxford.

LEWONTIN, R. C. (1993): Biology as Ideology: The Doctrine of DNA. Harper, New York.

LEYSHON, A., BURTON, D., KNIGHTS, D., ALFEROFF, C. and SIGNORETTA, P. (2004): 'Towards an ecology of retail financial services: understanding the persistence of door-to-door credit and insurance providers', Environment and Planning A 36: 625-45.

LEYSHON, A., SIGNORETTA, P., KNIGHTS, D., ALFEROFF, C. and BURTON, D. (2006): 'Walking with moneylenders: the ecology of the UK home-collected credit industry', Urban Studies 43: 161-86.

LUCAS, R. E. (1986): ‘Adaptive behavior and economic theory', Journal of Business 59: S401-26

LUSARDI, A. and MITCHELL, O. (2007): Baby boomer retirement security: the roles of planning, financial literacy, and housing wealth. WP2007-2, Pension Research Council, University of Pennsylvania, Philadelphia.

MCDOWELL, L. (2009): 'New masculinities and femininities: gender divisions in the new economy', in FURLONG, A. (ed.) Handbook of Youth and Young Adulthood: New Perspectives and Agenda. Routledge, London (forthcoming).

MCDOWELL, L., BATNITZKY, A., and DYER, S. (2008): 'Internationalization and the spaces of temporary labour: the global assembly of a local workforce', British Journal of Industrial Relations 46: 750-770. 
MCDOWELL, L., BATNITZKY, A., and DYER, S. (2009): 'Precarious work and economic migration: immigrant divisions of labour in Greater London's service sector', International Journal of Urban and Regional Research (forthcoming).

MILLER, D. (1992): 'Turning Callon the right way up', Economy and Society 31: 21833.

OAKSFORD, M. and CHATER, N. (2007): Bayesian Rationality: The Probabilistic Approach to Human Reasoning. Oxford University Press, Oxford.

OAKSFORD, M. and CHATER, N. (2009): Précis of Bayesian Rationality: The Probabilistic Approach to Human Reasoning. Behavioural and Brain Sciences 32: 69120.

PADOA-SCHIOPPA, C. (2008): 'The syllogism of neuro-economics', Economics and Philosophy 24: 449-57

PECK, J. (2005): 'Economic sociologies in space', Economic Geography 81: 129-76.

PECK, J. and THEODORE, N. (2007): 'Variegated capitalism', Progress in Human Geography 31: 731-72.

PETTIT, P. and MCDOWELL, J. (eds) (1986): Subject, Thought and Context. Oxford University Press, Oxford

POLANYI, K. (1944): The Great Transformation. Farrar \& Rinehart, New York.

RACHLIN, H. (2000): The Science of Self-Control. Harvard University Press, Cambridge, MA.

SAID, E. (1978): Orientalism. Random House, New York.

SCHICK, F. (1997): Making Choices. Cambridge University Press, Cambridge.

SCHWANEN, T. and ETTEMA, D. (2009): 'Coping with unreliable transportation when collecting children: examining parents' behaviour with cumulative prospect theory', Transportation Research A doi:10.1016/j.tra.2009.01.002.

SCOTT, A. J. (2006): 'A perspective of economic geography', in BAGCHI-SEN, S. and LAWTON SMITH, H. (eds): Economic Geography: Past, Present and Future. Routledge, London, pp. 56-80.

SCOTT, A. J. (2007): 'Capitalism and urbanization in a new key? The cognitive-cultural dimension’, Social Forces 85:1465-182. 
SCOTT, A. J. (2008): Social Economy of the Metropolis: Cognitive-Cultural Capitalism and the Global Resurgence of Cities. Oxford University Press, Oxford.

SCOTT, A. J. and POWER, D. (eds) (2004): Cultural Industries and the Production of Culture. Routledge, London.

SEDLEMEIER, S. and GIGERENZER, G. (2001): 'Teaching Bayesian reasoning in less than two hours', Journal of Experimental Psychology: General 130: 380-400

SHILLER, R. J. (2000): Irrational Exuberance. Princeton University Press, Princeton.

SHILLER, R. J. (2002): 'Bubbles, human judgement, and expert opinion', Financial Analysts Journal 58(3): 18-26.

SIMON, H. A. (1956): 'Rational choice and the structure of the environment', Psychology Review 63: 129-38.

SIMON, H. A. (1978): 'Rationality as process and product of thought', American Economic Review 68: 1-16.

SIMON, H. A. (1983): Reason in Human Affairs. Stanford University Press, Stanford.

SMITH, S. J. and EASTERLOW, D. (2005): 'The strange geography of health inequalities', Transactions, Institute of British Geographers NS30: 173-190

STRAUSS, K. (2008): 'Re-engaging with rationality: the context of UK pension decision-making', Journal of Economic Geography 8: 137-56.

STRAUSS, K. (2009): 'Cognition, context, and multi-method approaches to economic decision making', Environment and Planning A 41: 302-17.

SUPPES, P. (2003): 'Rationality, habits, and freedom', in DIMITRI, N., BASILI, M. and GILBOA, I. (eds): Cognitive Processes and Economic Behaviour. Routledge, London, pp. 137-167.

TETT, G. (2009): Fool's Gold: How Unrestrained Greed Corrupted a Dream, Shattered Global Markets and Unleashed a Catastrophe. Little Brown, London.

THALER, R. and SUNSTEIN, C. (2003): 'Libertarian paternalism', American Economic Review 93 (2): 175-97.

THALER, R. and SUNSTEIN, C. (2008): Nudge: Improving Decisions about Health, Wealth and Human Happiness. Caravan Books, New York.

THRIFT, N. J. (2004): 'Intensities of feeling: towards a spatial politics of affect', Geografiska Annaler B 86:57-78 
TVERSKY, A. and KAHNEMAN, D. (1974): 'Judgement under uncertainty: heuristics and biases', Science 185: 1124-31.

TVERSKY, A. and KAHNEMAN, D. (1991): 'Loss aversion in riskless choice: a reference dependent model', Quarterly Journal of Economics 106: 1039-61.

VIVES, X. (2008): Information and Learning in Markets: The Impact of Market Microstructure. Princeton University Press, Princeton.

WAGNER, R. K. (2002): 'Smart people doing dumb things: the case of managerial incompetence', in STERNBERG, R.J. (ed.): Why Smart People Can be so Stupid. Yale University Press, New Haven, pp. 42-63.

WINTER, S. G. (1986): 'Comments on Arrow and Lucas', Journal of Business 59: S42734.

WHITESIDE, N. (2003): 'Historical perspectives and the politics of pension reform', in CLARK, G. L. and WHITESIDE, N. (eds): Pension Security in the $21^{\text {st }}$ Century: Redrawing the Public-Private Divide. Oxford University Press, Oxford, pp. 21-43.

WILCOX, N. T. (2008): 'Against simplicity and cognitive individualism', Economics and Philosophy 24:523-32

WÓJCIK, D. (2009): 'Secondary markets' in CLARK, G. L., DIXON, A. and MONK, A. (eds): Managing Financial Risks: From Global to Local. Oxford University Press, Oxford, pp. 147-168. 